\title{
Study of plasma fibrinogen level and its relation to glycemic control in type-2 diabetes mellitus patients attending diabetes clinic at a tertiary care teaching hospital in Madhya Pradesh, India
}

\section{Parag Gupta*, Pawan Bhambani, Sanjeev Narang}

\begin{abstract}
Department of Pathology, Index Medical College Hospital \& Research Centre, Nemawar Road, Indore, Madhya Pradesh, India
\end{abstract}

Received: 18 July 2016

Accepted: 26 July 2016

\author{
*Correspondence: \\ Dr. Parag Gupta, \\ E-mail: guptadrparag@gmail.com
}

Copyright: ( ) the author(s), publisher and licensee Medip Academy. This is an open-access article distributed under the terms of the Creative Commons Attribution Non-Commercial License, which permits unrestricted non-commercial use, distribution, and reproduction in any medium, provided the original work is properly cited.

\begin{abstract}
Background: Diabetes mellitus comprises a group of common metabolic disorders where increased fibrinogen levels can act as a thrombogenic factor. Diabetic patients have higher cardiovascular morbidity than non-diabetic subjects. Several studies have shown that haemostatic factor especially hyperfibrinogenemia is implicated as a source of atherosclerosis and its complications.

Methods: A comparative observational study was conducted to compare fibrinogen levels between type 2 diabetes patients and healthy controls. Their fibrinogen levels were compared and co-related with glycemic status and other risk factors and parameters like glycosylated haemoglobin, age, sex, smoking, body mass index $\left(\mathrm{kg} / \mathrm{m}^{2}\right)$, hypertension and ischemic heart disease.

Results: It was seen that in the diabetic subset, the plasma fibrinogen levels are significantly higher than the nondiabetic subset (386.04 \pm 132.87 vs. 314.38 \pm 97.42 ; $\mathrm{p}<0.001)$. Our study re-established correlation between HbA1c and fibrinogen levels of the diabetic patient is positive i.e., poorer the glycemic status, higher the fibrinogen levels $(\mathrm{r}=0.24)$.

Conclusions: It can be concluded from the study that fibrinogen levels are in-creased in type 2 diabetic subjects with and without CHD. Plasma fibrinogen levels usually increased in type 2 diabetes, thus suggesting that hyperfibrinogenemia could contribute to the excess cardiovascular morbidity and mortality in this disease.
\end{abstract}

Keywords: Type 2 diabetes mellitus, Fibrinogen, Glycemic control, Lipid parameters, Cardiovascular risk factors

\section{INTRODUCTION}

Diabetes mellitus comprises a group of common metabolic disorders that share the phenotype of hyperglycemia. The worldwide prevalence of diabetes mellitus has risen dramatically over the past two decades and the prevalence of type 2 diabetes mellitus is expected to rise more rapidly in future because of increasing obesity and reduced activity levels. ${ }^{1}$ In the past decade, the potential role of hemostatic factors, particularly fibrinogen, in atherosclerosis and its complications has generated considerable attention. Studies have shown that formation of an occlusive thrombus, on a damaged atherosclerotic lesion is the most common precipitating factor of acute myocardial infarction. Evidence also suggests that fibrinogen has a role; both in the early stages of plaque formation and late complications of cardiovascular disease. ${ }^{2}$ The excess cardiovascular morbidity and mortality among diabetics have not been fully explained by major risk factors such as hypertension, cigarette smoking and hypercholesterolemia. Increased attention is being paid 
to, disordered hemostatic mechanism in pathogenesis of both large vessel and small vessel disease in diabetes. ${ }^{3}$ Impaired glucose tolerance exerts an influence by enhancing thrombogenic factors such as, fibrinogen in the diabetics. ${ }^{4}$ Fibrinogen, itself is determined by several modifiable and non-modifiable determinants like age, sex, smoking, body mass index (BMI), hypertension, alcoholism, glycemic control, lipid profile and urine albumin excretion rate. ${ }^{5,6}$

The present study was undertaken to know the levels of fibrinogen in type 2 diabetes mellitus and its relation with glycemic control. Diabetic patients have higher cardiovascular morbidity than non-diabetic subjects. Several studies have shown that haemostatic factor especially hyperfibrinogenemia is implicated as a source of atherosclerosis and its complications. ${ }^{7,8}$ Studies have reported that fibrinogen levels were higher in diabetics than in controls. ${ }^{3,4,5,9}$ In view of above concepts and due to paucity of similar studies in Indian patients, this study had been undertaken to know the significance of fibrinogen as risk factor in type 2 diabetes mellitus and its relation with glycemic control.

\section{METHODS}

The proposed comparative and cross-sectional observational study was conducted at Diabetic clinic, Index Medical College Hospital \& Research Centre, Nemawar Road, Indore. The subjects (type 2 DM patients) was drawn from among the patients who were attended Diabetic clinic, Index Medical College Hospital \& Research Centre, Nemawar Road, Indore and healthy subjects (age and sex matched) from relative accompanied with the patients in Diabetic OPD and nearby surrounding areas at Indore. The type $2 \mathrm{DM}$ patients and healthy subjects (age and sex matched) were included in group 1 and group 2 respectively for the study. Institutional Ethics Committee permission was sought. Individual informed consent was taken before enrolment subjects (including type 2 diabetes patients and healthy subjects) for the study. Clinical presentation, history of type 2 diabetes and other socio-demographic baseline data were collected by using pre-structured questionnaire in both type 2 diabetic patients and in controls. The various parameters which were studied include age of the patient (in years), sex, smoking history, blood pressure $(\mathrm{mm} \mathrm{Hg})$, BMI $\left(\mathrm{kg} / \mathrm{m}^{2}\right)$, history of ischemic heart disease (IHD), plasma fibrinogen levels (mg/dl) by "Clauss method" and glycosylated hemoglobin (\%) by" "immuno-turbidimetric test method". Blood Sugar levels (FBS, PPBS), plasma fibrinogen levels, glycated hemoglobin, and lipid profile (total cholesterol, triglycerides, HDL and LDL) were measured in both the cases and controls.

Fibrinogen level was measured by "Clauss method" using "Tulip Diagnostic (P) Ltd" fibrinogen kit. A calibration curve would be prepared by making serial dilutions of calibration plasma with Owren's veronal buffer ( 1 in 5,1 in 10,1 in 20 , and 1 in 40). $0.2 \mathrm{ml}$ of each dilution was warmed to $37^{\circ} \mathrm{C}$ for 3 minutes, then $0.1 \mathrm{ml}$ of bovine thrombin solution added, and the clotting time was measured. Each test was performed in duplicate, the average would be calculated and a calibration curve would be constructed (The clotting time in seconds against the fibrinogen concentration in $\mathrm{g} / \mathrm{l}$ ) on $\mathrm{log} / \mathrm{log}$ graph paper. The 1 in 10 dilution was considered to be $100 \%$ fibrinogen concentration. 1 in 10 dilutions was made from each patient's plasma, thrombin time would be measured as mentioned above, also in duplicate, and the fibrinogen level would be determined in $\mathrm{g} / \mathrm{l}$ from the calibration curve. ${ }^{10-13}$

HbA1C was measured by "particle enhanced immunoturbidimetric test" using Erba Manheim Kit and reader II. Glycosylated Hemoglobin $(\mathrm{GHb})$ is normal adult hemoglobin (HbA1) which is covalently bonded to a glucose molecule. $\mathrm{GHb}$ concentration is dependent on the average blood glucose concentration.Results were calculated automatically by the instrument. ${ }^{14,15}$

\section{Estimation of glucose and lipid profile parameters}

Fasting plasma glucose (FPG, ref. 75-100 mg/dl), serum total cholesterol (TC, ref. 130-250 mg/dl), triglyceride (TG, ref. $<160 \mathrm{mg} / \mathrm{dl}$ ), and high-density lipoprotein cholesterol (HDLC, ref. 30-55 mg/dl) were measured using commercially available kits (Oxidase-peroxidase method) in a spectrophotometer. Low-density lipoprotein cholesterol was calculated (c-LDL, ref. 70-165 mg/dl) by applying Freidewald's formula (c-LDL=[TC-TG/5]HDLC). Diabetes mellitus was defined as FPG of $\geq 126$ $\mathrm{mg} / \mathrm{dl}$ or as receiving anti-hyperglycemic drug treatment. $^{16}$

Data analyzed at the end of study. The data was arranged in a Microsoft Excel worksheet. Quantitative data were presented as mean \pm standard deviation, while qualitative data were demonstrated as frequency and percentage. The Student's t test was used to find the significant difference among the continuous variables between the 2 groups [diabetic patients in group 1 and healthy subjects in group 2]. Pearson correlation (r) was used to assess the degree of association between variables in different groups. Linear regression analysis was used to quantify the association between variables among different subgroups. $\mathrm{P} \leq 0.05$ was considered statistically significant and SPSS 17 was used for analyses (IBM SPSS 17 software, USA).

\section{RESULTS}

In the present study fibrinogen levels were estimated in 91 type 2 diabetes subjects (Group 1) and 96 (Group 2) age and sex matched controls. Fibrinogen levels were correlated with glycosylated hemoglobin (HbA1c).

The mean age in the cases and controls was 53.71 and 53.55 years respectively, with no significant difference in 
mean age (Table 1). The youngest age was 33 years. The eldest age was 78 years. The maximum numbers of patients were in the age group 51-70 years (67\%). Among the 91 patients studied $63.74 \%$ were males and $36.26 \%$ were females (Table 1). In this study M: F ratio is $1.74: 1$. The mean plasma fasting blood sugar level in type 2 diabetes patients or cases (Group 1) was 194.49 \pm 87.72 $\mathrm{mg} / \mathrm{dl}$. The mean plasma fasting blood sugar level in controls was $94.35 \pm 14.52 \mathrm{mg} / \mathrm{dl}$ (Table 2). Cases had a higher plasma fasting blood sugarlevel when compared to controls and normal range $(70-100 \mathrm{mg} / \mathrm{dl})$ and it was statistically highly significant $(\mathrm{P}<0.001)$ (Table 2$)$.

The mean plasma postprandial blood sugar level in type 2 diabetes patients (Group 1) was $345.65 \pm 116.72 \mathrm{mg} / \mathrm{dl}$ (Table 3). The mean plasma postprandial blood sugar level in controls was $141.73 \pm 44.33 \mathrm{mg} / \mathrm{dl}$. Cases had a higher plasma postprandial blood sugar level when compared to controls and it was statistically highly significant $(\mathrm{P}<0.001)$.
Table 1: Baseline characteristics of the study population.

\begin{tabular}{|llll|}
\hline Characteristics & $\begin{array}{l}\text { Patients with } \\
\text { type 2 } \\
\text { diabetes }\end{array}$ & $\begin{array}{l}\text { Control } \\
\text { Subjects }\end{array}$ & $\begin{array}{l}\text { p } \\
\text { value }\end{array}$ \\
\hline No of subjects & 91 & 96 & \\
\hline $\begin{array}{l}\text { Mean age } \\
\text { (in yrs) }\end{array}$ & $53.61 \pm 11.99$ & $53.55 \pm 11.66$ & 0.97 \\
\hline Male (n) & $58(63.74 \%)$ & $61(63.54 \%)$ & \\
\hline Female (n) & $33(36.26 \%)$ & $35(36.46 \%)$ & \\
\hline Hypertension & $32(35.16 \%)$ & Nil & \\
\hline IHD & $13(14.29 \%)$ & Nil & \\
\hline Smoking & $21(23.08 \%)$ & $17(17.71 \%)$ & \\
\hline Weight (Kg) & $68.69 \pm 10.36$ & $66.23 \pm 7.47$ & 0.063 \\
\hline Height (meters) & $1.65 \pm 0.06$ & $1.66 \pm 0.06$ & 0.2561 \\
\hline BMI & $25.23 \pm 3.96$ & $24.03 \pm 1.95$ & 0.0088 \\
\hline
\end{tabular}

Table 2: Student's t test comparing fasting blood sugar (FBS) value between the case (n=91) and control group $(\mathbf{n}=96)$.

\begin{tabular}{|llllll|}
\hline & N & Mean & Std. deviation & Std. error mean & p-value \\
\hline FBS1 (Group 1) & 91 & 194.4945 & 87.71613 & 9.19515 & 0.001 \\
\hline FBS2 (Group 2 or Control) & 96 & 94.3542 & 14.52401 & 1.48235 & \\
\hline
\end{tabular}

Table 3: Student's t test comparing postprandial blood sugar (PPBS) value between the case (n=91) and control group $(\mathbf{n = 9 6 )}$.

\begin{tabular}{|llllll|}
\hline & $\mathbf{N}$ & Mean & Std. deviation & Std. error mean & p-value \\
\hline PPBS 1 (cases) & 91 & 345.6484 & 116.72031 & 12.23561 & 0.001 \\
\hline PPBS 2 (controls) & 96 & 141.7292 & 44.33924 & 4.52535 & \\
\hline
\end{tabular}

Table 4: Student's t test comparing fibrinogen levels between the diabetic subset $(n=91)$ and control group ( $n=96)$.

\begin{tabular}{|lllll|l|}
\hline & N & Mean & Std. deviation & Std. error mean & p-value \\
\hline Fibrinogen 1 (Cases) & 91 & 386.0440 & 132.86484 & 13.92802 & \multirow{2}{*}{0.001} \\
\hline Fibrinogen 2 (Controls) & 96 & 314.3750 & 97.41731 & 9.94261 & \\
\hline
\end{tabular}

The study parameters in the two groups are shown in (Table 4). It was seen that in the diabetic subset, the plasma fibrinogen levels are significantly higher than the non-diabetic subset $(386.04 \pm 132.87$ vs. $314.38 \pm 97.42 ; \mathrm{p}<0.001)$.

Table 5-8 shows the comparison of the various parameters in between the two groups. It was seen that the diabetic subset had significantly higher levels of total serum cholesterol $(196.53 \pm 36.19$ vs. 166.02 \pm 27.08 ; p $=0.001)$, LDL levels (130.67 \pm 35.69 vs. $102.97 \pm 27.30 ; \mathrm{p}=0.001)$, and HDL levels $(38.88 \pm 5.03$ vs. $43.51 \pm 2.19 ; \mathrm{p}=0.001)$. The triglyceride levels were also higher $(141.92 \pm 51.23$ vs. $99.53 \pm 31.65 ; \mathrm{p}=0.001)$ in the diabetic subset than control group. Aberrations in lipid profile were more in diabetic subjects than control group. Further, dyslipidemia with regard to TC and atherogenic lipoprotein was higher in diabetic female subjects than male diabetic subjects. Thus this data highlights that dyslipidemia is a common feature in diabetes which should be monitored to avert cardiovascular events.

The mean HbA1C level in type 2 diabetes patients (Group 1) was 9.66 \pm 2.60 (Table 9). The mean HbA1C level in controls was 5.49 \pm 0.27 . Cases had a higher HbA1C level when compared to controls and normal range (4-6\%) and it was statistically highly significant $(\mathrm{P}<0.0001)$. The mean HbA1c values indicated poor metabolic control among the diabetics. 
Table 5: Student's t test comparing LDL levels between the diabetic subset $(n=91)$ and control group $(n=96)$.

\begin{tabular}{|llllll|}
\hline & N & Mean & Std. deviation & Std. error mean & p-value \\
\hline LDL Gr. 1 & 91 & 130.6813 & 35.69061 & 3.74139 & 0.001 \\
\hline LDL Gr. 2 & 96 & 102.9688 & 27.30354 & 2.78666 & 0.001 \\
\hline
\end{tabular}

Table 6: Student's t test comparing HDL levels between the diabetic subset $(n=91)$ and control group (n=96).

\begin{tabular}{|llllll|} 
& $\mathbf{N}$ & Mean & Std. deviation & Std. error mean & p-value \\
\hline HDL Gr.1 & 91 & 38.8791 & 5.03065 & 0.52736 & 0.001 \\
\hline HDL Gr. 2 & 96 & 43.5104 & 2.19087 & 0.22360 & \\
\hline
\end{tabular}

Table 7: Student's t test comparing triglyceride levels between the diabetic subset $(n=91)$ and control group ( $n=96)$.

\begin{tabular}{|llllll|} 
& $\mathbf{N}$ & Mean & Std. deviation & Std. error mean & p-value \\
\hline TGL Gr.1 & 91 & 141.9231 & 51.23350 & 5.37073 & 0.001 \\
\hline TGL Gr.2 & 96 & 99.5313 & 31.65004 & 3.23027 & \\
\hline
\end{tabular}

Table 8: Student's t test comparing cholesterol levels between the diabetic subset $(n=91)$ and control group ( $n=96)$.

\begin{tabular}{|llllll|} 
& N & Mean & Std. deviation & Std. error mean & p-value \\
\hline CHOL Gr.1 & 91 & 196.5275 & 36.18666 & 3.79339 & 0.001 \\
\hline CHOL Gr.2 & 96 & 166.0208 & 27.07610 & 2.76344 & \multirow{2}{*}{0.0010} \\
\hline
\end{tabular}

Table 9: Student's t test comparing HbA1C levels between the diabetic subset $(n=91)$ and control group (n=96).

\begin{tabular}{|llllll|} 
& N & Mean & Std. deviation & Std. error mean & p-value \\
\hline HbA1C Group 1 & 91 & 9.6648 & 2.60480 & 0.27306 & 0.001 \\
\hline HbA1C Group 2 & 96 & 5.4937 & 0.27099 & 0.02766 & 0 \\
\hline
\end{tabular}

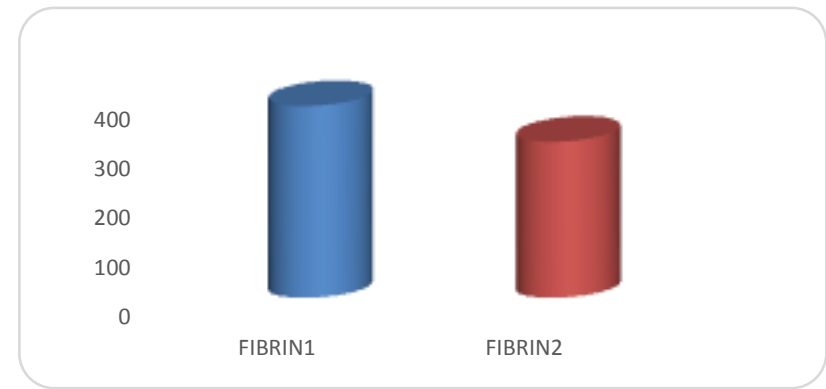

Figure 1: Bar diagram showing relationship between mean plasma fibrinogen levels in diabetics (Fibrin 1) \& controls (Fibrin 2).

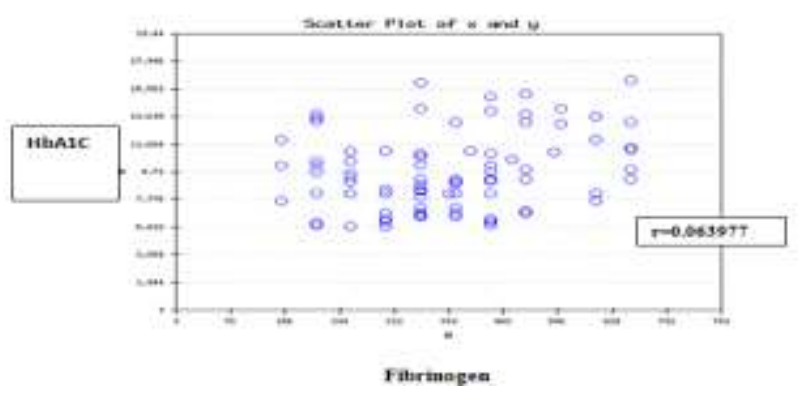

Figure 2: Scattered diagram showing correlation between mean HbA1C and plasma fibrinogen in diabetics.

\section{DISCUSSION}

In the present study diabetics had higher fibrinogen level than controls signifying increased cardiovascular risk. The various possible mechanisms for hyperfibrinogenemia in diabetics could be that a procoagulant state often exists in people of diabetes.

The mechanisms by which fibrinogen increases cardiovascular risks are not fully understood. Fibrinogen plays important role in development of atherosclerosis starting from the stage of plaque formation till formation of occlusive thrombus over a ruptured atherosclerotic plaque, which is the most common precipitating cause of MI. The various mechanism by which fibrinogen has been found to promote atherosclerosis and thrombosis are (a) hyperfibrinogenemia increases plasma viscosity, (b) it induces reversible RBC aggregation, (c) it binds it receptors on platelet membrane and causes platelet aggregation, (d) it forms fibrin and fibrinogen degradation products (FDPs) which in turn bind LDL and sequester more fibrinogen and (e) fibrinogen and FDPs stimulate smooth cell proliferation and migration. ${ }^{17,18}$

All these factors result in increased atherogenesity in patients of hyperfibrinogenemia i.e., diabetes and cause coronary artery disease. Besides, fibrinogen levels were 
found to be associated with age, smoking, HTN, BMI, glycemic control and IHD. ${ }^{18}$ The correlation between glycemic control and fibrinogen levels could be due to (a) glycosylate fibrinogen is less susceptible to plasmin degradation (b) relative insulin deficiency in diabetic's results in differential protein synthesis i.e., $29 \%$ decrease in albumin synthesis and 50\% increase in fibrinogen synthesis. ${ }^{19}$ Thus, a link between fibrinogen and atherosclerosis is undeniable; it is the nature of association that is debatable-risk factor or risk marker. Several determinants of fibrinogen in health and disease are life style dependent, e.g. BMI, smoking etc., and are amenable to change. The value of lowering fibrinogen levels by life style modifications or drugs is still unknown and future cardiovascular research in this area is warranted.

In our cross sectional study, we studied the different blood parameters in patients of type 2 diabetics and compared the results with the non-diabetic healthy population. We found significantly higher levels of cholesterol, LDL and triglycerides in the diabetic population (group 1); also, the fibrinogens were significantly higher in diabetics in comparison to normal healthy volunteers. The results from our study showed fibrinogen to be significantly higher in diabetic patients who also had coronary artery disease than those who had only diabetes. Our study also showed fibrinogen to be significantly higher in patients with diabetes than the control. James et al and Bembde AS et al found fibrinogen to be higher in diabetic patients than the control. $^{17,20}$ They also showed fibrinogen to be higher in patients with coronary artery disease than without the disease.

Our study showed fibrinogen to be significantly associated with the glycocylated hemoglobin (HbA1c) (Figure 2). Fibrinogen level increased as the value of HbA1c became higher. We did not find any significant association between duration of diabetes and fibrinogen level but fibrinogen level was significantly associated with glycaemic control (HbA1c).

Fibrinogen is also a marker of altered vascular physiology in diabetes. ${ }^{21}$ A study from Italy showed that diabetic subsets had increased levels of fibrinogen and that it correlated with the HbA1c levels. ${ }^{21}$ In our study, we did find this correlation (Figure 2). The fibrinogen levels were also found to correlate with a higher risk of ischaemic stroke, which was independent of the blood glucose levels. ${ }^{22}$

In our study, age was correlated to the fibrinogen levels, with a statistical significance $(\mathrm{p}=0.001)$. Fibrinogen was also elevated in hypertensive or IHD with diabetic patients in our study (Table 1). Different studies have also found this link between hypertension and the fibrinogen levels, which is probably due to increased viscosity. $^{23}$
In our study we observed that in the diabetic subset, the plasma fibrinogen levels are significantly higher than the non-diabetic subset $(386.04 \pm 132.87$ vs. $314.38 \pm 97.42$; $\mathrm{p}<0.001$ ) (Table 4/Figure 1). We, therefore, hypothesized that hyperfibrinogenemia is possibly linked to the underlying inflammation in T2DM and its associated vascular complications. High plasma fibrinogen levels were associated with an increased risk of cardiovascular disease in healthy as much as in high-risk individuals. Thus, there is strong and unequivocal evidence from epidemiological studies that plasma fibrinogen levels are independently related to the presence of, and the subsequent development of, vascular disease. ${ }^{24}$

Our study also re-established correlation between HbA1c and fibrinogen levels of the diabetic patient is positive i.e., poorer the glycemic status, higher the fibrinogen levels $(r=0.24)$, (Figure 2).

Plasma fibrinogen levels usually increased in type 2 diabetes, thus suggesting that hyperfibrinogenemia could contribute to the excess cardiovascular morbidity and mortality in this disease. ${ }^{3,25-29}$ However, the mechanisms leading to increased fibrinogen concentration in type 2 diabetic patients remain unknown. In particular, the dynamics of fibrinogen synthesis/secretion in vivo are poorly understood, and they have never been directly investigated in type 2 diabetes.

Since our study was cross-sectional, it was limited in its ability to find out the relative importance of the above factors in risk stratification. Association between fibrinogen and HbA1c was weak among type 2 diabetic group which was possibly the result of very small sample size. For that, prospective studies with a relatively larger patient population are needed.

\section{CONCLUSION}

In this study, the type 2 diabetic patients with or without other cardiovascular diseases were found to have significantly higher levels of fibrinogen in comparison to non-diabetic control subjects. These variables also correlated with the vascular risk markers like age, blood pressure and blood glucose. However, this association was weak among type 2 diabetic group which was possibly the result of very small sample size.

The actual impact of these newer risk factors needs to be assessed by doing larger prospective studies. However, this study shows that these newer risk factors can be measured in diabetic patients for a better risk prediction. Also, the need for better blood pressure and blood sugar control has to be emphasized.

Our observation supports the hypothesis that inflammation and impaired fibrinolysis may play a pathogenetic role in T2DM and its associated micro and macrovascular complications. Strong association between fibrinogen and glycemic status also points to the fact that 
fibrinogen may be considered as an inflammatory marker in T2DM. Understanding the dysglycemia- inflammationcoagulation paradigm may be useful in lowering the future cardiovascular risk in T2DM. Smaller sample size and nature of the study design were the major drawbacks of our study. Furthermore, we did not study the effect of drugs as well as other anthropometric parameters, which might have influenced our outcome. Therefore, our results need to be interpreted with caution, and future prospective studies are needed to validate our findings.

Funding: No funding sources

Conflict of interest: None declared

Ethical approval: The study was approved by the Institutional Ethics Committee

\section{REFERENCES}

1. Alvin CP. Diabetes Mellitus. In: Braunwald E, Faucei AS, Kasper DL, Hauser SL, Longo DL, Larry JJ (eds) Harrison's principles of internal medicine. $15^{\text {th }}$ ed. New York: McGraw Hill Medical Publishing division; 2001:2109-2137.

2. Bruno G, Cavallo-perin P, Bargero G, Borra M, Errico ND, Pagano G. Association of fibrinogen with glycemic control and albumin excretion rate in patients with non-Insulin-dependent diabetes mellitus. Ann Intern Med. 1996;125:653-7.

3. Fuller JH, Keen H, Jarrett RJ, Omer T, Meade TW, Charkrabarti R. Haemostatic variables associated with diabetes and its complications. $\mathrm{Br}$ Med $\mathrm{J}$. 1979;2:964-6.

4. Kannel BW, Wilson WF, Belanger AJ, Gagnon Dr, D'Agostino BD. Diabetes, fibrinogen, and risk of cardiovascular disease: the Framingham experience. JAMA. 1987;258:1183-6.

5. Anjula J, Gupta HL, Narayan S. Hyperfibrinogenemia in patients of diabetes mellitus in relation to glycemic control and urinary albumin excretion rate. JAPI. 2001;49:227-30,

6. Ernst E, Ludwig KR. Fibrinogen as a cardiovascular risk factor: a meta-analysis and review of literature. Ann Intern Med. 1993;118:956-63.

7. Wilhelmsen L, Suardsudd K, Kristoffer KB, Larson B, Lennart W, Jibblin G. Fibrinogen as a risk factor for stroke and myocardial infarction. N Engl J Med. 1984;311:501-5.

8. Thompson WD, Smith EB. Atherosclerosis and coagulation system. J Pathol. 1989;159:97-106.

9. Mittal S, Dwivedi RN, Lalchandani A, Puri A, Mishra P. Correlation of fibrinogen as an indicator of both long and short term glycemic control in diabetes. JAPI. 2002;50:129-30.

10. Biggs R, McFarlane R G. Human blood coagulation and its disorders. 3d ed. F.A. Davis Company, Philadelphia; 1962:474.

11. Quick AJ. Hemorrhagic diseases and thrombosis. 2nd ed. Philadelphia: Lea and Febiger; 1966:460.

12. Schmidt RM, Fairbanks VF, editors. Electrophoretic mobilities of mutant hemoglobins and mutant globin chains. In: Schmidt RM, Fairbanks VF, eds. CRC handbook series in clinical laboratory science, Section 1: Haematology, Volume III, Boca Raton, Florida, USA: CRC Pr I Llc; 1980:125-139.

13. Dacie J V, Lewis S M. Practical Haematology, 8th ed. Churchill Livingstone Publications; 1995:305.

14. Sachs DB. Carbohydrates. In: Burtis CA, Ashwood ER, editors. Tietz Textbook of Clinical Chemistry. 3rd ed. Philadelphia: W.B. Saunders Company; 1999:790-796.

15. Jeppsson JO, Kobold U, Barr J, Finke A, Hoelzel $\mathrm{W}$, Hoshino $\mathrm{T}$, et al. Approved IFFC reference method for the measurement of HbA1c in human blood. Clin Chem Lab Med. 2002;40:78-89.

16. American Diabetes Association. Standards of medical care in diabetes-2011. Diabetes Care. 2011;34(Suppl 1):S11-61.

17. Bembde AS. A study of plasma fibrinogen level in type-2 diabetes mellitus and its relation to glycemic control. Indian $\mathrm{J}$ Hematol Blood Transfus. 2012;28(2):105-8.

18. Brownlee M, Ulassara H, Cerami A. Nonenzymatic glycosylation reduces the susceptibility of fibrin to degradation by plasmin. Diabetes. 1983;32:680-4.

19. Pierpaola DF, Margaret GG, Haymond MW. Differential effects of insulin deficiency on albumin and fibrinogen synthesis in humans. J Clin Invest. 1991;88:833-40.

20. Stec JJ, Silbershatz H, Tofler GH, Matheney TH, Sutherland P, Lipinska I, et al. Association of fibrinogen with cardiovascular risk factors and cardiovascular disease in the framingham offspring population. Circulation. 2000;102:1634-8.

21. Haffner SM. The metabolic syndrome: inflammation, diabetes mellitus, and cardiovascular disease. Am J Cardiol. 2006;97:3A-11.

22. Di Napoli M, Papa F, Bocola V. Prognostic influence of increased C-reactive protein and fibrinogen levels in ischaemic stroke. Stroke. 2001;32:133-8.

23. Letcher RL, Chien S, Pickering TG, Sealey JE, Laragh JH. Direct relationship between blood pressure and blood viscosity in normal and hypertensive subjects. Role of fibrinogen and concentration. Am J Med. 1981;70:1195-202.

24. Maresca G, Di Blasio A, Marchioli R, Di Minno G. Measuring plasma fibrinogen to predict stroke and MI: an update. Arterioscler Thromb Vasc Biol. 1999;19:1368-77.

25. Kannel WB, D'Agostino RB, Wilson PW, Belanger AJ, Gagnon DR. Diabetes, fibrinogen, and the risk of cardiovascular disease: the Framingham experience. Am Heart J. 1990;120(3):672-6.

26. Ganda OP, Arkin CF. Hyperfibrinogenemia. An important risk factor for vascular complications in diabetes. Diabetes Care. 1992;15:1245-50.

27. Missov RM, Stolk RP, van der Bom JG, Hofman A, Bots ML, Pols HA, et al. Plasma fibrinogen in NIDDM. The Rotterdam Study. Diabetes Care. 1996;19:157-9. 
28. Garcia MJ, McNamara PM, Gordon T, Kannel WB. Morbidity and mortality in diabetes in the Framingham population: sixteen year follow-up study. Diabetes. 1974;23:105-11.

29. Kannel WB, McGee DL. Diabetes and cardiovascular disease. The Framingham Study. JAMA. 1979:241:2035-8.
Cite this article as: Gupta $\mathrm{P}$, Bhambani $\mathrm{P}$, Narang S. Study of plasma fibrinogen level and its relation to glycemic control in type- 2 diabetes mellitus patients attending diabetes clinic at a tertiary care teaching hospital in Madhya Pradesh, India. Int J Res Med Sci 2016;4:3748-54. 